\title{
Análise de fósforo no recurso hídrico da microbacia hidrográfica da Fazenda Glória, Taquaritinga, SP
}

\author{
Flavia Mazzer Rodrigues ${ }^{1}$ \\ Teresa Cristina Tarlé Pissarra ${ }^{2}$ \\ Sérgio Campos ${ }^{3}$ \\ ${ }^{1}$ Universidade Estadual Paulista \\ Via de Acesso Prof. Paulo Donato Castellane, s/n - Jaboticabal - SP, Brasil \\ teresap@fcav.unesp.br \\ ${ }^{2}$ Universidade Estadual Paulista \\ Via de Acesso Prof. Paulo Donato Castellane, s/n - Jaboticabal - SP, Brasil \\ flamazzer@hotmail.com \\ ${ }^{3}$ Universidade Estadual Paulista \\ Rua José Barbosa de Barros, no 1780 - Jaboticabal - SP, Brasil \\ seca@fca.unesp.br
}

\begin{abstract}
The analysis of the way in hydrographic basins requires knowledge of the processes and characteristics of variable in different geographic scales. Leaving of the principle that the hydrographic basins can be hierarchy, those territorial units of ideal work for the analysis of the hydrological conditions are considered. This work had for objective to carry through a comparison of the conditions of waters resources in four hydrographic basins, with different use and occupation. Five points of sampling throughout the net of draining in the hydrographic basins of $1^{\mathrm{a}}$ had been established magnitude order. Comparatively, in the hydrographic basins M2 and M3 bigger variability of the evaluated parameters occurred. The characterization of the hydrological conditions of the hydrographic basins indicated that the agricultural activities, including practical the cultural ones in the productive system had affected the quality of the waters resources.
\end{abstract}

Palavras-chave: recurso hídrico, ambiente, monitoramento ambiental.

\section{INTRODUÇÃO}

O desenvolvimento sustentável e a conservação dos recursos naturais são temas amplamente discutidos e difundidos nos mais diversos níveis da sociedade. Pois a cada dia percebe-se mais e mais, sua indissociável relação com a qualidade de vida. $\mathrm{O}$ crescimento demográfico e a expansão das atividades agropecuárias no mundo destacam-se como causas do aumento no consumo e deterioração dos recursos naturais. A água e o solo são considerados recursos naturais renováveis, entretanto, devido ao uso inadequado do solo há uma quantidade excessiva de poluentes que pressionam a capacidade de absorção e regeneração do sistema (microbacia hidrográfica) a níveis que praticamente impossibilitam sua recuperação (Landim, 1997).

A degradação progressiva do ambiente causa as deteriorações físicas, sociais, econômicas e ambientais nas bacias hidrográficas, onde a natureza responde com erosão, 
assoreamento, enchentes. Andreolli (2003) ressaltam que à medida que as atividades humanas alteram os componentes do ciclo hidrológico de uma bacia, ocorre à interferência no regime hídrico, na quantidade e qualidade da água, e este fato afeta significativamente a produção e disponibilidade hídrica.

Segundo Moraes \& Jordão (2002), nas últimas décadas, esse precioso recurso vem sendo ameaçado pelas ações indevidas do homem, o que acaba resultando em prejuízo para a própria humanidade. Apesar de todos os esforços para armazenar e diminuir o seu consumo, a água está se tornando, cada vez mais, um bem escasso, e sua qualidade se deterioram cada vez mais rápido.

O recurso hídrico, por possuírem características dinâmicas, dentro da bacia hidrográfica, sofre as conseqüências das atividades desenvolvidas pelo homem, e a sua qualidade resulta das influências do clima, geologia, fisiografia, solos, vegetação, e, principalmente do manejo dos sistemas produtivos agrícolas e desenvolvimento urbano. Nas áreas onde atividades antrópicas são desenvolvidas, como a agricultura, o uso do solo contribui consideravelmente nas características físicas, químicas e biológicas da água.

As alterações das características físico-químicas em um corpo hídrico são, ainda mais, preocupantes, quando este corpo hídrico apresenta uma estação de captação para abastecimento público. As características mantidas em certos limites de padrões viabilizam seu uso, são esses limites que constituem os critérios, ou padrões da qualidade da água.

A degradação da maioria dos mananciais superficiais, o grau de comprometimento de sua qualidade e a diminuição de sua disponibilidade, originada pela má gestão das bacias hidrográficas é agravada pela falta de informações que promovem um diagnóstico da real condição desses mananciais.

Neste contexto, nas bacias hidrográficas com cobertura no solo, a vegetação minimiza consideravelmente a erosão do solo, a sedimentação, a lixiviação excessiva de nutrientes e a elevação da temperatura da água, (Sopper, 1975). Dentre estas áreas, as nascentes protegidas por matas são reconhecidas como mananciais da mais elevada qualidade para o abastecimento doméstico, para a proteção das comunidades aquáticas e outros benefícios. Por outro lado, as práticas que se seguem após a retirada destas áreas de proteção, tendem a produzir uma degradação intensa e prolongada das condições hídricas, (Brown, 1988).

Como as áreas florestadas não perturbadas são as melhores condições desejadas do ponto de vista da proteção dos recursos hídricos, o monitoramento hidrológico em microbacias com mata serve como referência para comparação com outras microbacias impactadas, simultaneamente monitoradas. A boa gestão da água deve ser objeto de um plano que contemple os múltiplos usos desse recurso, desenvolvendo e aperfeiçoando as técnicas de utilização, tratamento e recuperação dos mananciais.

Desta forma, as análises químico-físicas do solo e da água irão inferir na importância, que se refere ao grau de significância do impacto em relação ao fator ambiental afetado (recurso hídrico), no estado evolutivo (critério que sugere a situação do impacto), na fonte (se o impacto é localizado ou difuso), na distribuição (descreve a regularidade do impacto no meio) e na acumulação ao longo do tempo em relação ao fator afetado.

Neste sentido, a avaliação do uso/ocupação do solo em microbacias hidrográficas utilizando variáveis de qualidade de água, é uma tentativa que todo programa de monitoramento de recursos naturais prevê como forma de acompanhar, através de informações resumidas, a possível degradação dos recursos naturais ao longo do tempo (Toledo \& Nicolella, 2002).

Com base nesse contexto, foram selecionados cinco pontos de amostragem ao longo da rede de drenagem na Bacia Hidrográfica do Córrego da Fazenda Glória, no Município de 
Taquaritinga, SP, com o objetivo de comparar a variação no tempo do parâmetro fósforo e determinar as condições hidrológicas da área de estudo.

\section{MATERIAL E MÉTODOS}

A área experimental localiza-se na Microbacia Hidrográfica do Córrego da Fazenda Glória, Município de Taquaritinga - SP, localizada no Planalto Ocidental Paulista, centro norte do Estado de São Paulo, entre as latitudes $21^{\circ} 18^{\prime} \mathrm{S}$ e $21^{\circ} 33^{\prime} \mathrm{S}$ e longitudes $48^{\circ} 14^{\prime} \mathrm{W}$ Gr. e $48^{\circ} 44^{\prime} \mathrm{W}$ Gr. O Córrego da Fazenda Glória nasce na Serra do Jaboticabal, em Taquaritinga, e deságua à montante do Córrego Rico. Esta microbacia é uma das mais importantes do Município e está inserida na Bacia Hidrográfica do Córrego Rico, vinculada ao Comitê de Bacias Hidrográficas do Rio Mogi-Guaçú, segundo a Divisão Hidrográfica do Estado de São Paulo, (Figura 1).

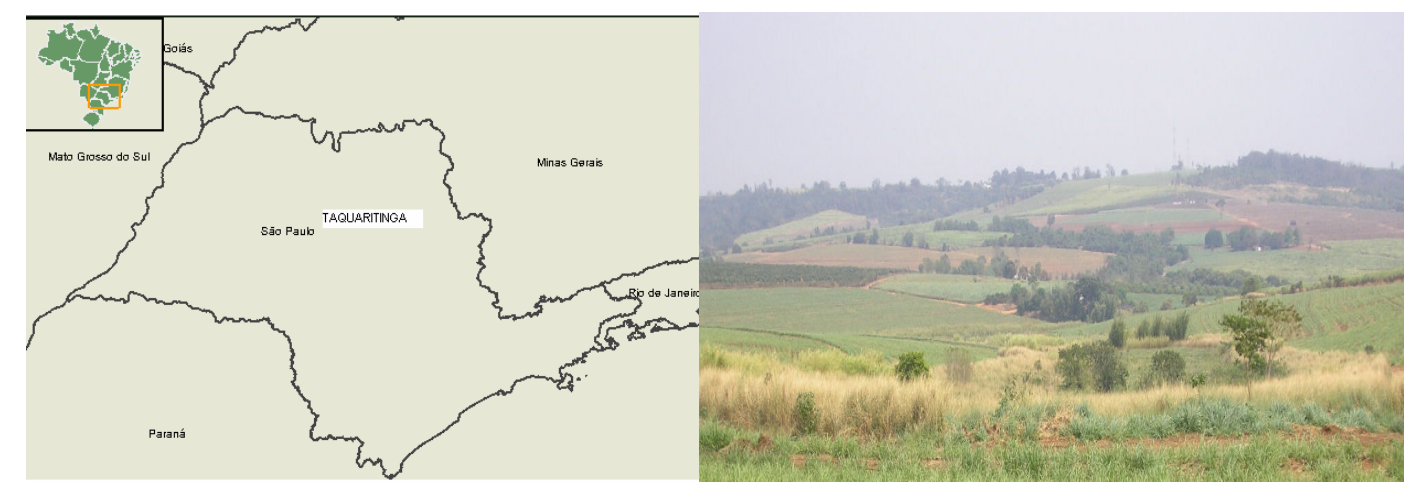

Figura 1 - Localização e vista geral da área experimental, Bacia Hidrográfica do Córrego da Fazenda Glória, Município de Taquaritinga, SP.

A Microbacia Hidrográfica do Córrego da Fazenda Glória é considerada de $4^{\text {a }}$ ordem de magnitude e é constituída de 07 microbacias hidrográficas de $2^{\mathrm{a}}$ ordem e 02 microbacias hidrográficas de $3^{\text {a }}$ ordem de magnitude.

Esta microbacia foi escolhida por sua representatividade na região em importância agrícola, com características socioeconômicas rurais, e por ser a única a apresentar fragmentos naturais de Mata Atlântica. É uma área de cabeceira com formação natural, drenada por um curso d'água, a montante de uma secção transversal considerada, para onde converge toda a água de escoamento.

O clima é classificado, de acordo com o sistema de classificação de Köppen, como mesotérmico úmido de verão quente (Cwa), Comissão de Solos CNPA (1960). A precipitação varia entre 1.100 e $1.700 \mathrm{~mm}$ anuais. A temperatura média do mês mais quente é sempre superior a $22^{\circ} \mathrm{C}$ e a do mês mais frio, inferior a $18^{\circ} \mathrm{C}$. O material geológico da área é constituído de arenitos com cimento calcário classificado como da formação Bauru $(\mathrm{Kb}-$ cretácio superior) (Instituto Geográfico e Geológico, 1963). Apresenta conformação relativamente movimentada, sendo o relevo classificado como suave ondulado e ondulado, (colinas amplas e médias) com declives longos e em algumas áreas forte ondulado. Apresenta linhas de "cuestas" que segundo Penteado \& Ranzani (1971) delimitam parte do bordo superior do planalto de Jaboticabal. Os solos de ocorrência na área de acordo com Oliveira et al. (1999) são classificados como Argissolos Vermelho - Amarelos. A vegetação originária é 
composta pela Floresta Latifoliada Tropical. Na área ocorrem fragmentos de mata e as principais culturas produtivas são: m..nga, limão, goiaba, laranja e cana-de-açúcar.

Para a avaliação do recurso hídrico foram considerados como pontos de coleta quatro microbacias hidrográficas de $1^{\underline{a}}$ ordem de magnitude e uma foz (Figura 2).

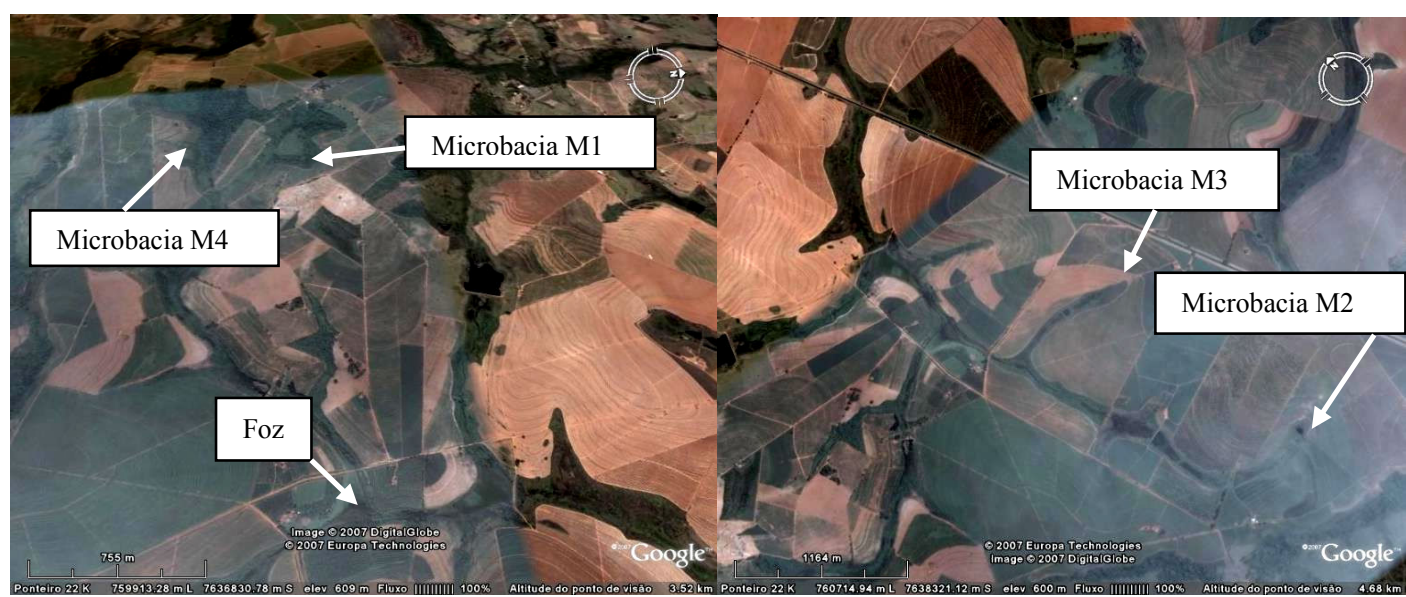

Figura 2 - Rede de Drenagem da Microbacia do Córrego da Fazenda Glória, Município de Taquaritinga, SP., com os pontos M1, M2, M3, M4 e Foz 1.

Nesta microbacia foram consideradas como pontos de coleta de dados quatro microbacias hidrográficas de $1^{\mathrm{a}}$ ordem de magnitude e 1 foz.

- Microbacia de $1^{\mathrm{a}}$ ordem de magnitude (M1) - água coletada na nascente, o entorno protegido por mata (Figura 2).

- Microbacia de $1^{\text {a }}$ ordem de magnitude (M2 e M3) - água coletada na nascente da microbacia com o entorno alterado por cultura agrícola, predominante de cana-deaçúcar, sem vegetação nativa (Figura 2).

- Microbacia de $1^{\mathrm{a}}$ ordem de magnitude (M4) - água coletada na nascente represada com o entorno de reflorestamento em estágio inicial e plantio de palmito (Figura 2).

- Foz 1 (F1) - água coletada na foz das microbacias hidrográficas M1 e M4, para a comparação das condições hidrológicas de áreas com proteção da vegetação nativa e sem a ação dessa proteção (Figura 2).

A seleção dos pontos de coleta foi idealizada no intuito de analisar o fósforo e determinar as condições de qualidade da água. Justifica-se a seleção das microbacias hidrográficas de $1^{\mathrm{a}}$ ordem de magnitude pelo tipo de uso e ocupação do solo ao redor de suas nascentes, para que a água analisada não receba influência direta de outra cobertura vegetal.

As amostras de água superficial, dos córregos de $1^{\mathrm{a}}$ ordem, foram coletadas utilizando um recipiente "limpo", de plástico, com capacidade volumétrica de até 2 Litros, abertos no momento da coleta e fechados logo a seguir, tomando-se o devido cuidado para não incluir partículas grandes, detritos, folhas ou outro tipo de material acidental. Para determinação do fósforo total foi utilizado um fotocolorímetro digital microprocessador com resolução de espectrofotômetro para análises gerais de água, equipamento completo de fácil operação, marca ALFAKIT. As amostras foram analisadas no Laboratório de Biodigestão Anaeróbica do Departamento de Engenharia Rural, ambos da FCAV/UNESP, Câmpus de Jaboticabal.

$\mathrm{O}$ fósforo foi analisado ao longo do tempo (meses do ano - caracterizando os períodos de chuvas e seca) e no espaço (microbacias hidrográficas). A coleta de dados do recurso hídrico foi obtida na forma de valores médios mensais, concordado com Tucci (1993) e 
Arcova e Cicco (1999). O uso e ocupação do solo foram diagnosticados e atualizados por tomadas fotográficas da área e levantamento das práticas agrícolas adotadas durante o período de coleta de dados.

\section{RESULTADOS E DISCUSSÃO}

A qualidade do recurso hídrico em aspectos físicos e químicos é derivada, principalmente, pela infiltração das águas no solo e pela localização dessas águas na formação litológica e sua exposição à superfície, e à matéria orgânica em geral. O clima é um componente extremamente importante para os processos metabólicos dos ambientes. Apresenta-se uma análise inicial do clima no primeiro período de coleta dos dados, por ser, na discussão, fundamental para a compreensão de determinados eventos que ocorrem principalmente nas vertentes e rede de drenagem das microbacias hidrográficas. Na Figura 3 observa-se a distribuição mensal da precipitação pluviométrica e da temperatura na região durante o período de estudo, registrados pela Coopercitrus (Cooperativa de Cafeicultores e Citricultores do Estado de São Paulo.

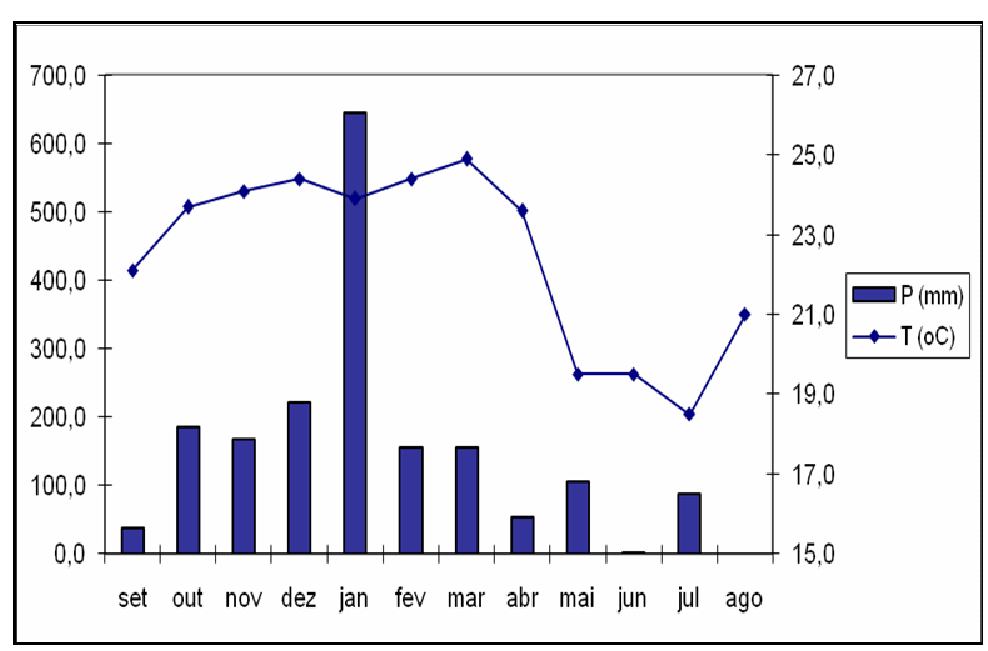

\begin{tabular}{ccc}
\hline \hline Mese & $\mathbf{P}$ & \\
$\mathbf{S}$ & $(\mathbf{m m})$ & $\left.\mathbf{T} \mathbf{(}^{\mathbf{0}} \mathbf{C}\right)$ \\
set & 37,6 & 22,1 \\
out & 184,5 & 23,7 \\
nov & 166,8 & 24,1 \\
dez & 221,0 & 24,4 \\
jan & 644,6 & 23,9 \\
fev & 154,7 & 24,4 \\
mar & 156,3 & 24,9 \\
abr & 53,7 & 23,6 \\
mai & 105,7 & 19,5 \\
jun & 2,5 & 19,5 \\
jul & 87,7 & 18,5 \\
ago & 0,0 & 21,0 \\
\hline \hline
\end{tabular}

Figura 3 - Distribuição mensal da precipitação pluviométrica e da temperatura do ar na região de Taquaritinga durante o período de estudo (Set/06-Ago/07). Fonte: Coopercitrus.

A precipitação média anual foi de $1815,1 \mathrm{~mm}$. A distribuição seguiu um padrão, com maior precipitação na época de verão e menor no inverno, variando de $0 \mathrm{~mm}$ em agosto e $644,6 \mathrm{~mm}$ em janeiro. A distribuição da temperatura apresentou temperaturas mais baixas no inverno e mais altas no verão, com a mínima de $18,5^{\circ} \mathrm{C}$ em julho e máxima de $24,9{ }^{\circ} \mathrm{C}$ em março.

A caracterização do fósforo do recurso hídrico nas microbacias hidrográficas de $1 .^{\text {a }}$ ordem de magnitude do Córrego da Fazenda Glória, Município de Taquaritinga, SP., no período de agosto de 2006 a agosto de 2007 (Tabela 2). 
Tabela 1 - Caracterização do fósforo do recurso hídrico nas microbacias hidrográficas M1, M2, M3 e M4 e Foz (F1) das microbacias M1 e M4, pertencentes da Microbacia Hidrográfica do Córrego da Fazenda Glória, Município de Taquaritinga, S.P. (Período: Ago/06-Ago/07).

\begin{tabular}{cc}
\hline \hline $\begin{array}{c}\text { Microbacia } \\
\text { Hidrográfica }\end{array}$ & $\begin{array}{c}\text { Fósforo } \\
(\mathbf{m h} / \mathbf{L})\end{array}$ \\
\hline M1 & $0,92 \mathrm{a}$ \\
M2 & $0,47 \mathrm{a}$ \\
M3 & $0,71 \mathrm{a}$ \\
M4 & $0,86 \mathrm{a}$ \\
F1 & $0,97 \mathrm{a}$ \\
Média & 0,78 \\
Máximo & 0,97 \\
Mínimo & 0,47 \\
DP & 0,181 \\
CV(\%) & 23,022 \\
\hline \hline
\end{tabular}

O fósforo nas águas de bacias hidrográficas florestadas resulta principalmente da lixiviação do solo e da rocha e da decomposição da matéria orgânica.

$\mathrm{Na}$ água, ele pode ser encontrado na forma orgânica ou inorgânica. A fertilização por adubos pode contribuir para a elevação do fósforo.

No período das chuvas ocorre o arraste das partículas para o curso d'água e há menores valores de concentração de fósforo (Figura 4). No período de seca há menor volume de água e maior concentração de fósforo. Relacionando com $\mathrm{pH}$ acima de 6,0, o fósforo é liberado para a solução do solo, ocorrendo um aumento da concentração no recurso hídrico neste período, Sharpley et al. (1975).

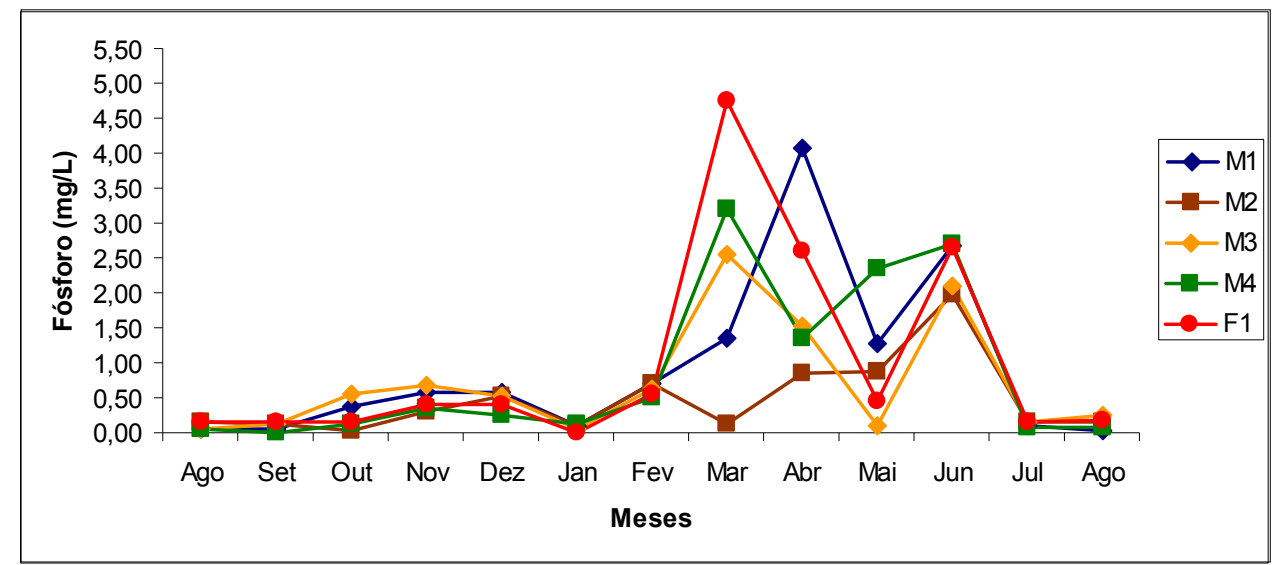

Figura 4 - Variação do fósforo da água na Microbacia Hidrográfica do Córrego da Fazenda da Glória, Taquaritinga, S.P., durante o período de estudo (Ago/06-Ago/07).

Cunha e Guerra (2003) afirmam que somente as características naturais da bacia hidrográfica, através da topografia, geologia, solos e clima, já podem contribuir para a erosão potencial das encostas e para os desequilíbrios ambientais. Como o fósforo pode ser oriundo de adubos, da decomposição de matérias orgânica, de detergentes, de material particulado presente na atmosfera ou da solubilização de rochas, verificou-se que no período de maior 
concentração deste elemento estava ocorrendo movimentação com práticas agrícolas, como plantio e adubação da cana-de-açúcar na vertente das microbacias, semelhantes ao observado por Pelegrinni (2005).

\section{CONCLUSÃO}

A caracterização da condição hidrológica das microbacias hidrográfias indica que as atividades agrícolas, incluindo as práticas culturais no sistema produtivo interferem no recurso hídrico da rede de drenagem da Microbacia Hidrógrafica do Córrego da Fazenda Glória.

\section{BIBLIOGRAFIA}

ANDREOLLI, I. Previsão de Vazão em Tempo Real no Rio Uruguai com Base na Previsão Meteorológica. Porto Alegre, 2003. 182p. Dissertação (Mestrado em Recursos Hídricos), Universidade Federal do Rio Grande do Sul, 2003.

ARCOVA, F.C.S. Balanço hídrico, características do deflúvio e calibragem de duas microbacias hidrográficas na Serra do Mar, SP. Piracicaba, 1996. 130p. Dissertação (Mestrado em Agronomia) - Escola Superior de Agricultura Luiz de Queiroz. Universidade de São Paulo, 1996.

ARCOVA, F.C. S, CICCO, V. de.. Qualidade da água de microbacias com diferentes usos do solo na região de Cunha, Estado de São Paulo. Scientia Florestalis, v.56, p.125-134. 1999.

BRAGA, B.; HESPANHOL, I.; CONEJO, J.G.L. Introdução à engenharia ambiental. $2^{\text {a }}$ ed. São Paulo, Pearson Prentice Hall, 318 p., 2005.

BRANCO, S. M. Hidrologia aplicada à engenharia sanitária. $3^{\text {a }}$ ed. São Paulo, CETESB/ASCETESB, 640 p., 1986.

BROWN, G.W. Forestry and water quality. 2.ed. Oregon, 1988. 142p.

CARVAlHO, N. de O.; FILIZOLA JUNIOR, N. P.; SANTOS, P. M. C. dos; LIMA, J. E. F. W. Guia de avaliação de assoreamento de reservatórios. Brasília: ANEEL / Superintendência de Estudos e Informações Hidrológicas, 2000. 132p.

COMISSÃO DE SOLOS. Levantamento de reconhecimento dos solos do Estado de São Paulo: contribuição à carta de solos do Brasil. Centro Nacional de Ensino e Pesquisas Agronômicas. Boletim Serviço Nacional Pesquisa Agronômica. Rio de Janeiro, n.12, 1960.634p.

ESTEVES, F. A. Fundamentos de limnologia. $2^{\mathrm{a}}$ ed. Rio de Janeiro: Interciência, FINEP, 1988. 575 p.

KUMMER, A.C.B.; ANDRADE, L.D.; SOMMER, R.S.; LOURENÇO, I.; BOHNENBERGER, L; ANGST, F.; GOMES, S.D. Análise de parâmetros físicos ao longo do rio Cascavel. In: CONGRESSO BRASILEIRO DE ENGENHARIA AGRÍCOLA, 26, Bonito, MS, 2007. Cd.

LANDIM, P.M.B. Recursos naturais não renováveis e desenvolvimento sustentável. In: MARTOS, H.L., MAIA, N.B. (Coord). Indicadores ambientais. Sorocaba: Bandeirantes Indústria Gráfica S.A., 1997.p9-13.

LEONARDO, H.C.L. Indicadores de qualidade de solo e água para avaliação do uso sustentável da microbacia hidrográfica do rio Passo Cue, Região Oeste do Estado do Paraná. Piracicaba, 2003. 131p Dissertação (Mestrado em Recursos Florestais). Escola Superior de Agricultura Luiz de Queiroz, ESALQ/USP, 2003.

MOLINA, P.M. Diagnóstico da qualidade e disponibilidade de água na microbacia do córrego Água da Bomba no Município de Regente Feijó, São Paulo. Ilha Solteira, 2006. 160p Dissertação (Mestrado em Engenharia Civil ênfase em Recurso Hídrico e Tecnologia Ambiental). Faculdade de Engenharia de Ilha Solteira, UNESP - Universidade Estadual Paulista, 2006.

MORAES, D. S. de L.; JORDÃO, B. Q. Degradação de recursos hídricos e seus efeitos sobre a saúde humana. Revista Saúde Pública, São Paulo, v. 36, n. 3, 2002. 
OLIVEIRA, J.B. de; CAMARGO, M.N.; ROSSI, M.; CALDERANO FILHO, B. Mapa pedológico do Estado de São Paulo: legenda expandida. Campinas: Instituto Agronômico; Rio de Janeiro: Embrapa - Solos, 1999. 64 p.

PATEMIANI, J.E.S.; PINTO, J.M. Qualidade da água. In: MIRANDA, J.H.; PIRES, R.C.M. Irrigação série Engenharia Agrícola. Ed. Piracicaba: FUNEP/SBEA, v.1, p.195-253, 2001.

PELLEGRINI, J.B.R. Fósforo na água e no sedimento na microbacia hidrográfica do Arroio Lino, Agudo, R.S. Santa Maria, 2005. 124p. Dissertação (Mestrado em Ciência do Solo - Processos Químicos). Universidade Federal de Santa Maria, 2005.

PENTEADO, M.M.; RANZANI, G. Aspectos geomorfológicos e os solos do Município de Jaboticabal. Gegraphica, Lisboa, n.25, p. 41-61, 1971.

ROCHA, C.M.B.M.; RODRIGUES, L. S. dos; COSTA, C.C. Avaliação da qualidade da água e percepção higiênico-sanitária na área rural de Lavras, Minas Gerais, Brasil, 1999-2000. Caderno Saúde Pública, v.22, n.9, p.1967-1978, 2006.

SHARPLEY, A.N. Phosphorus cycling in unfertilized and fertilized agricultural soils. Soil Science Society of American Journal, Madison, v.49, p.905-911, 1985.

SOPPER, W.E. Effects of timber harvesting and related management practices on water quality in forested watersheds. Journal of Enviromental Quality, v.4, n.1, p.24-29, 1975.

TOLEDO, G.L., NICOLELLA, G. Índice de qualidade de água em microbacia sob uso agrícola e urbano. Embrapa Meio Ambiente, Scientia Agricola, v.59, n.1, p.181-186, 2002.

TUCCI, C.E.M. Hidrologia: ciência e aplicação. Porto Alegre: Editora da Universidade: ABRH: EDUSP, 1993.

TUNDISI, J. G. Água no século XXI: Enfrentando a escassez. São Paulo: Rima, 2003. 247p.

VANZELA, L.S. Qualidade da água para a irrigação na microbacia do córrego três Barras no Município de Marinópolis, São Paulo. Ilha Solteira, 2004. 105p Dissertação (Mestrado em Agronomia - Sistema de Produção). Faculdade de Engenharia de Ilha Solteira, UNESP, 2004. 